\title{
Atenolol in the prophylaxis of chronic migraine: a 3-month open-label study
}

\author{
Bengt Edvardsson
}

\begin{abstract}
Background: Chronic migraine (CM) is a type of chronic daily headache. CM presents a challenge to primary care physicians and neurologists. Any new treatment showing efficiency would therefore be of great importance. Atenolol together with other beta-blockers is a first-line choice in episodic migraine prophylaxis. Clinical findings support the efficacy of atenolol in doses of 50 to $200 \mathrm{mg} /$ day.

Methods: Here I present an open-label study the aim of which is to evaluate the efficacy and tolerability of atenolol (50 mg o.d) for the prevention of CM. 19 patients affected by CM were studied.

Results: Following a one-month run-in period, the patients took atenolol for 3 months. Mean numbers of headache days per month were reduced from $20.1 \pm 2.4$ during the run-in period to $7.8 \pm 6.1$ by month 1.5 and to $7.1 \pm 5.7$ by the $3 r d$ month of treatment $(p<0.0003)$. There was a significant difference between 1.5 months and the $3 r d$ month $(p<0.006)$. The severity of attacks was reduced from a mean $2.3 \pm 0.6$ to $1.4 \pm 1.1(p<0.010)$ at 1.5 months. In this, there was no difference between 1.5 months and the 3rd month. In 5 (29\%) of the17 patients who completed the study, CM was totally gone during the 3rd month of treatment. No patient was totally unresponsive to the drug. Among the patients who completed the study, the treatment was well tolerated and the compliance was good.
\end{abstract}

Conclusion: Atenolol seems to be a safe and effective treatment for CM. Controlled trials are needed to confirm the observed results.

Keywords: Headache; Migraine; Chronic migraine; Chronic daily headache; Beta blockers; Atenolol

\section{Introduction}

Chronic migraine (CM) is a type of chronic daily headache. CM presents a challenge to primary care physicians and neurologists. The overall cost of migraine to society is large (Hu et al. 1999). Any new treatment showing efficiency is thus of great importance.

$\mathrm{CM}$ was a new addition to the revised International Classification of Headache Disorders (ICHD) criteria published in 2004 (Headache Subcommittee of the International Headache Society 2004). The criteria for CM were revised in 2006 and are included in the appendix of the current classification (Headache Classification Committee, Olesen et al. 2006). CM patients often require multiple drugs and nondrug treatment modalities. The pathophysiology of CM is not clear; however the

Correspondence: Bengt.Edvardsson@med.lu.se

Department of Neurology, Faculty of Medicine, Skane University Hospital, S-221 85 Lund, Sweden basic underlying pathophysiology is the disposition to migraine without aura. The prognosis and treatment of patients with $\mathrm{CM}$ are variable.

Most preventive agents used for CM have not been examined in well designed double-blind studies (Olesen et al. 2006). Atenolol is together with other betablockers a first-line choice in episodic migraine prophylaxis. Clinical findings support the efficacy of atenolol in doses of 50 to $200 \mathrm{mg} /$ day (Olesen et al. 2006). Results from three trials confirm the benefit of atenolol in episodic migraine prophylaxis. (Stensrud et al. 1980) in their study found no statistically significant difference between atenolol $50 \mathrm{mg}$ b.i.d. and propranolol $80 \mathrm{mg}$ b.i.d. Atenolol was more effective than placebo. Another study (Forssman et al. 1983) reported that the effect of atenolol $100 \mathrm{mg}$ o.d. was significantly better than that of placebo. Interestingly, the intake of ergotamine products was significantly lower in all patients using such drugs. (Johannsson et al. 1987)

\section{Springer}

(c) 2013 Edvardsson; licensee Springer. This is an Open Access article distributed under the terms of the Creative Commons Attribution License (http://creativecommons.org/licenses/by/2.0), which permits unrestricted use, distribution, and reproduction in any medium, provided the original work is properly cited. 
also confirmed that the effect of atenolol $100 \mathrm{mg}$ o.d. is significantly better than that of placebo. Few side effects were reported with both atenolol and placebo. The study showed atenolol to be safe and effective in the prophylactic treatment of episodic migraine.

The aim of this open-label study was to evaluate the possible efficacy and tolerability of atenolol in the prophylaxis of CM.

\section{Material and methods}

For this open-label prospective study a sample of $19 \mathrm{pa}-$ tients were enrolled, aged 19-32 years (5 M, 14 F). All patients satisfied the criteria for CM (Headache Classification Committee, Olesen et al. 2006). Patients having the diagnosis $\mathrm{CM}$ with medication overuse were excluded. Patients were consecutively recruited from the Outpatient department of the Department of Neurology at Skane University Hospital, Lund.

Inclusion criteria were: initial onset of $\mathrm{CM}$ at least 1 year before and patients over 18 years of age. Exclusion criteria were: other headaches but migraine, other forms of chronic pain, overuse of pain/migraine medication, psychiatric diseases, neurological diseases and other chronic diseases, intake of CNS-active medications the last 3 months before the selection, intake of prophylactic medication for migraine the last 3 months before the selection, intake of other regular medications, pregnancy or risk of pregnancy and inability/unwillingness to cooperate. An informed consent was obtained from each participant. Characteristics of patients enrolled are displayed in Table 1.

After a one-month run-in period, patients received atenolol as treatment in a low dose (50 mg o.d.) for 3 months. The inclusion criteria were re-examined at the end of the run-in period. The patients were free to take symptomatic medication, if needed. Headache days per month and severity (rated as: 1, mild; 2, moderate; and 3 , severe) of migraine attacks were recorded by the patients in a headache diary. Headache days per month

\section{Table 1 Characteristics of the population studied}

\begin{tabular}{ll}
\hline Sex & \\
Male & 5 \\
Female & 14 \\
Age (years) & \\
Mean & 25.1 \\
Median & 25 \\
Range & $19-32$ \\
Disease (years) & \\
Mean & 3,1 \\
Median & 3 \\
\hline
\end{tabular}

were the main outcome measure and the principal index used to evaluate the efficacy. Headache days and severity during the run-in period was compared with what was found after 1.5 months and during the 3rd month of therapy. The Wilcoxon signed rank test (a nonparametric test) was used for the statistical analysis. Differences were considered significant when P value was less than 0.05. Adverse events were reported during the period.

\section{Results}

Two patients out of 19 enrolled left the study because of adverse events: fatigue and dizziness. 17 patients completed the treatment period of 3 months. Mean headache days per month were reduced from $20.1 \pm 2.4$ during the run-in period to $7.8 \pm 6.1$ at 1.5 months and to $7.1 \pm 5.7$ by the 3rd month of treatment $(\mathrm{p}<0.0003)$. There was a significant difference between 1.5 months and the 3rd month $(\mathrm{p}<0.006)$ (Figure 1). The severity of attacks was reduced from mean $2.3 \pm 0.6$ to $1.4 \pm 1.1(\mathrm{p}<0.010)$ at 1.5 months. There were no difference between 1.5 months and the 3rd month (Figure 2). In 5 (29\%) of the17 patients who completed the study, CM was totally gone at the 3rd month of treatment. No patient was totally unresponsive to the drug. No significant adverse effects were reported among the patients who completed the study. Baseline systolic blood pressure and heart rate did not differ considerably during the period. The medication had no effects on activities of daily living and the patients reported improved quality of life due to relief of symptoms.

\section{Discussion}

This is an open label study made to evaluate the possible efficacy and tolerability of atenolol in CM. The results in the study indicate benefit in preventing CM by significantly reducing the number of headache days per month at 1.5 months and in the 3rd month of treatment compared with the run-in period. Atenolol was also able to significantly reduce the severity of the attacks at 1.5 months and in the 3rd month of treatment compared with the run-in period. To my knowledge, this is the first prospective study of atenolol as preventive treatment for CM.

The study contradicts earlier results in CM. No betablocker has a Class I study showing effectiveness in reducing CM (Couch 2011). Up to know, only topiramate and local injections of botulinum toxin have shown efficacy in large placebo-controlled randomized trials (Couch 2011).

However, these results are in accordance with previous studies including migraineurs in whom an effect of prophylactic atenolol has been shown. Beta-blockers are approximately $50 \%$ effective in producing a $>50 \%$ reduction in attack frequency (Stensrud \& Sjaastad 1980; Forssman et al. 1983; Johannsson et al. 1987; Olesen et al. 2006). Propranolol is effective in migraine prevention at a daily dose of $80-240 \mathrm{mg}$ (Barbanti et al. 2011). 


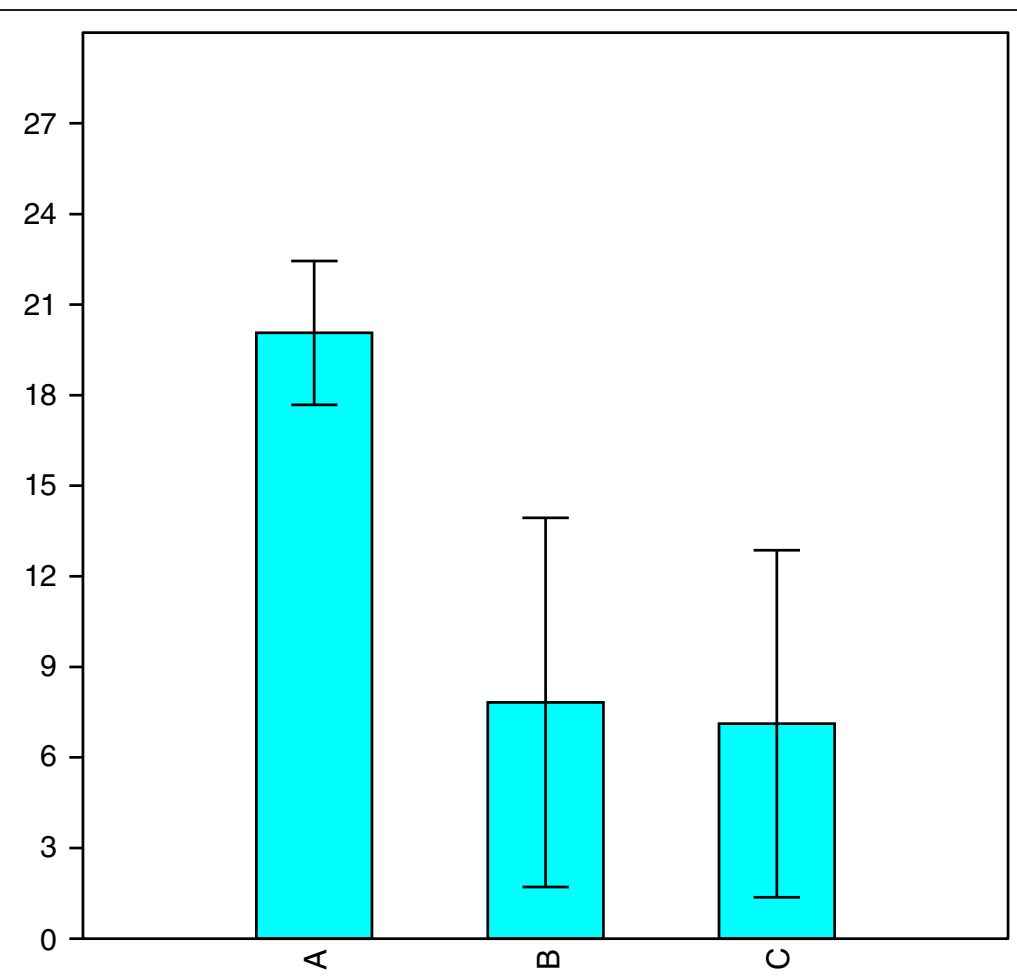

Figure 1 Mean $( \pm \mathrm{SD})$ headache days per month. $(\mathrm{A})$ and at 1.5 months $(\mathrm{B})$ and month 3 (C).

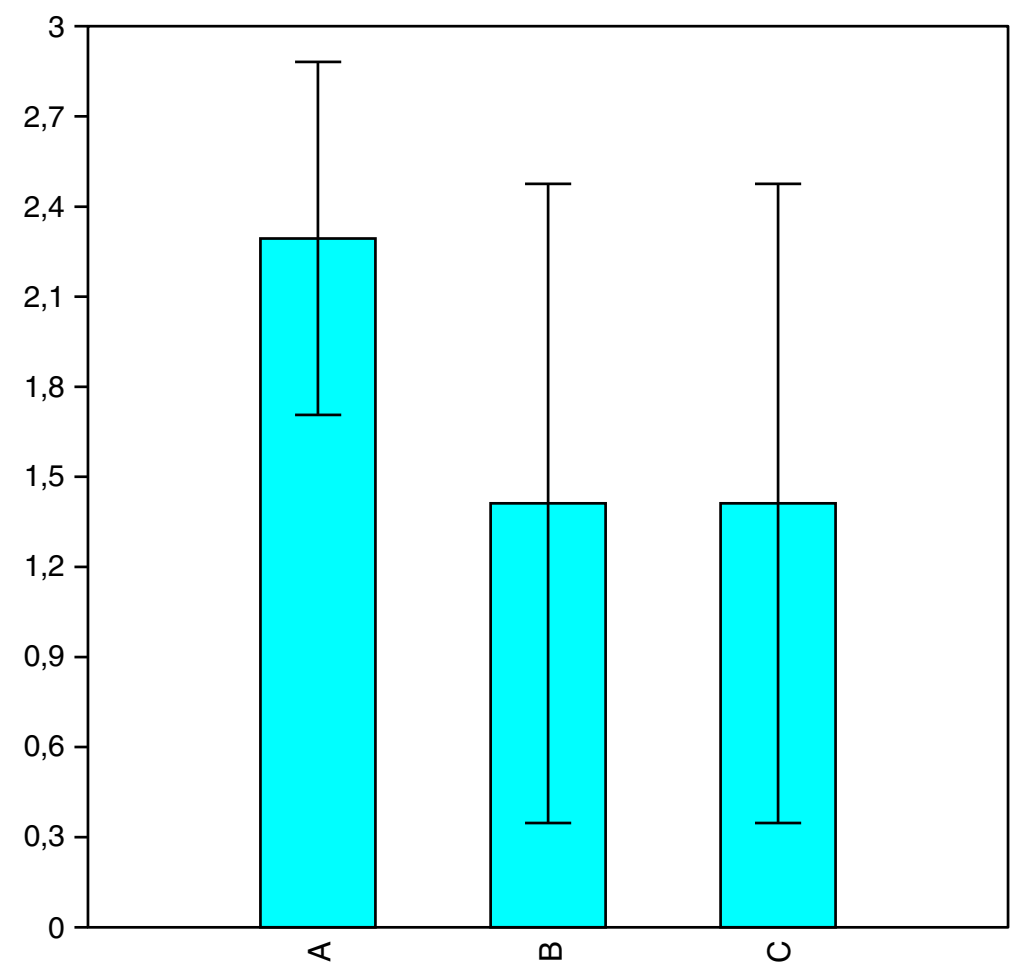

Figure 2 Mean ( \pm SD) severity of migraine attacks during the study. (A) and at 1.5 months (B) and month 3 (C). 
A Cochrane review of studies 2004 concluded that propranolol is effective in preventing migraine in the short term (Barbanti et al. 2011). The relative efficacy of the different beta-blockers has not been established. Most studies show no significant difference between drugs.

The action of beta-blockers is most likely central. Blockade of $\beta 1$-mediated effects and consequent inhibition of $\mathrm{Na}^{+}$release and tyrosine hydroxylase activity are considered the main mechanisms of action. Beta-blockers reduce the neuronal firing rate of noradrenergic neurons of the locus coeruleus, regulate the firing rate of PAG neurons and probably interact with the serotonergic system by blocking 5-HT2C and 5-HT2B receptors. It has been hypothesized that beta-blockers exert some of their prophylactic effects in migraine through an action at the ventroposteromedial thalamic nucleus and inhibition of cortical spreading depression (Barbanti et al. 2011).

Earlier studies have shown that compared with episodic migraine, patients suffering from $\mathrm{CM}$ are more likely to be depressed, anxious, suffering from other forms of chronic pain, and overusing acute pain medications. Epidemiologic and clinical research consistently documents an association between depressive, bipolar, and anxiety disorders with migraine (Diener et al. 2011; Olesen et al. 2006). All beta-blockers can cause behavioural adverse events as fatigue, lethargy and depression (Nappi \& Moskowitz 2011). Because propranolol may predispose to depression, its use as an antimigraine preventive agent is limited (Couch 2011). However, in this study the subjects showed no signs of depression. The subjects were young and otherwise healthy. No medication overuse was found. These facts may have contributed to the good efficacy results.

Atenolol is associated with risks for pregnant and lactating women as well as for diabetics. Studies have shown that women with chronic hypertension that is treated with atenolol have higher rates of intrauterine growth restriction and preterm delivery (Orbach et al. 2013). Atenolol is also associated with significant effects on some nursing infants and should be given to nursing mothers with caution. There is one report of hypotension, bradycardia, and cyanosis in a breast-fed infant of a mother taking $100 \mathrm{mg}$ daily (Hutchinson et al. 2013). Beta- blockers are also contraindicated in patients with brittle diabetes mellitus (Olesen et al. 2006).

Although the patients were observed prospectively, the study has limitations. It is limited by its small sample size and open-label nature. The good efficacy results obtained here must be interpreted with caution, as they come from an open research in a condition with a high placebo response. Nevertheless, the patients were carefully selected and all patients satisfied the criteria for CM. In the study, the persistence of therapeutic effect (29\% of patients being headache-free since the run-in period) can hardly be attributed to a placebo effect only.

\section{Conclusion}

Atenolol seems to be a safe and effective treatment for CM. Further investigations with double-blind, placebocontrolled randomized trials would be of value in order to assess the real efficacy of atenolol as a new therapeutic option for preventing $\mathrm{CM}$.

\section{Consent}

Written informed consent was obtained from the patient for the publication of this report and any accompanying images.

\section{Abbreviations}

PAG: Pontomesencephalic dorsolateral periaqueductal gray matter; 5-HT2C: 5-hydroxytryptamine, 5-HT2C), Serotonin (5-HT) 2C receptors; 5-HT2B: 5-hydroxytryptamine, 5-HT2B), Serotonin (5-HT) 2B receptors.

\section{Competing interests}

The author declares that he has no competing interests.

\section{Author contribution}

$\mathrm{BE}$ is the only contributor to the study.

\section{Acknowledgments}

I would like to thank medical student Johanna Melkersson Bulacz, Lund University, Lund, Sweden, for help with the preparation of the table.

The author takes full responsibility for the data presented in this study, analysis of the data, conclusions, and conduct of the research. The author had full access to those data and has maintained the right to publish any and all data independent of any third party.

Received: 26 April 2013 Accepted: 19 September 2013

Published: 22 September 2013

\section{References}

Barbanti P, Aurilia C, Egeo G, Fofi L (2011) Migraine prophylaxis: what is new and what we need? Neurol Sci 32(Suppl 1):S111-S115

Couch JR (2011) Update on chronic daily headache. Curr Treat Options Neurol 13:41-55

Diener HC, Holle D, Dodick D (2011) Treatment of chronic migraine. Curr Pain Headache Rep 15:64-69

Forssman B, Lindblad GJ, Zborkinova V (1983) Atenolol for migraine prophylaxis. Headache 23:188-190

Headache Classification Committee, Olesen J, Bousser MG, Diener HC, Dodick D, First M, Goadsby PJ et al (2006) New appendix criteria open for a broader concept of chronic migraine. Cephalalgia 26:742-746

Headache Classification Subcommittee of the International Headache Society (2004) The international classification of headache disorders. Cephalalgia 24(Suppl 1):1-160

Hu XH, Markson LE, Lipton RB, Stewart WF, Berger ML (1999) Burden of migraine in the United States: disability and economic costs. Arch Intern Med 159:813-818

Hutchinson S, Marmura MJ, Calhoun A, Lucas S, Silberstein S, Peterlin BL (2013) Use of common migraine treatments in breast-feeding women: a summary of recommendations. Headache 53:614-627

Johannsson V, Nilsson LR, Widelius T, Jäverfalk T, Hellman P, Akesson JA et al (1987) Atenolol in migraine prophylaxis a double-blind cross-over multicentre study. Headache 27:372-374

Nappi G, Moskowitz MA (2011) Handbook of clinical neurology, Headache, volume 97. Elsevier, Amsterdam 
Olesen J, Tfelt-Hansen P, Welch KMA, Goadsby PJ, Ramadan NM (2006) The headaches, 3rd edn. Lippincott Williams \& Wilkins, Philadelphia

Orbach H, Matok I, Gorodischer R, Sheiner E, Daniel S, Wiznitzer A et al (2013) Hypertension and antihypertensive drugs in pregnancy and perinatal outcomes. Am J Obstet Gynecol 208:301e1-301e6

Stensrud P, Sjaastad O (1980) Comparative trial of Tenormin (atenolol) and Inderal (propranolol) in migraine. Headache 20:204-207

doi:10.1186/2193-1801-2-479

Cite this article as: Edvardsson: Atenolol in the prophylaxis of chronic migraine: a 3-month open-label study. SpringerPlus 2013 2:479.

\section{Submit your manuscript to a SpringerOpen ${ }^{\circ}$} journal and benefit from:

- Convenient online submission

- Rigorous peer review

- Immediate publication on acceptance

- Open access: articles freely available online

- High visibility within the field

- Retaining the copyright to your article

Submit your next manuscript at $\gg$ springeropen.com 